\title{
Sirolimus: Efficacy and Complications in Children With Hyperinsulinemic Hypoglycemia: A 5-Year Follow-Up Study
}

\author{
Güemes Maria, ${ }^{1,2}$ Dastamani Antonia, ${ }^{1}$ Ashworth Michael, ${ }^{3}$ Morgan Kate, ${ }^{1}$ \\ Ellard Sian, ${ }^{4}$ Flanagan E Sarah, ${ }^{4}$ Dattani Mehul, ${ }^{1,2}$ and Shah Pratik ${ }^{1,2}$ \\ ${ }^{1}$ Endocrinology Department, Great Ormond Street Hospital for Children NHS Foundation Trust, \\ London WC1N 3JH, United Kingdom; ${ }^{2}$ Section of Genetics and Epigenetics in Health and Disease, \\ Genetics and Genomic Medicine Programme, University College London Great Ormond Street Hospital \\ Institute of Child Health, London WC1N 1EH, United Kingdom; ${ }^{3}$ Histopathology Department, Great \\ Ormond Street Hospital for Children NHS Foundation Trust, London WC1N 3JH, United Kingdom; and \\ ${ }^{4}$ Institute of Biomedical and Clinical Science, University of Exeter Medical School, Exeter EX1 2LU,
} United Kingdom

*G.M. and D.A. contributed equally to this work.

Introduction: Sirolimus, a mammalian target of rapamycin inhibitor, has been used in congenital hyperinsulinism (CHI) unresponsive to diazoxide and octreotide. Reported response to sirolimus is variable, with high incidence of adverse effects. To the best of our knowledge, we report the largest group of CHI patients treated with sirolimus followed for the longest period to date.

Methods: Retrospective study of CHI patients treated with sirolimus in a tertiary service and review of the 15 publications reporting CHI patients treated with mammalian target of rapamycin inhibitors. Comparison was made between the findings of this study with those previously published.

Results: Twenty-two CHI patients treated with sirolimus were included in this study. Twenty showed partial response, one showed complete response, and one was unresponsive. Five of the partially/fully responsive patients had compound heterozygous $A B C C 8$ mutations and five had heterozygous $A B C C 8$ mutations. A total of $86.4 \%$ (19/22) developed complications, with infection being the most frequent (17/ $22)$, of which 11 were of bacterial etiology, followed by persistent diarrhea (3/22) and hyperglycemia (2/ 22). Seventeen patients stopped sirolimus: 13 from infections; 2 from hyperglycemia; and 2 from alternative treatment (lanreotide) response. Compared with data previously published, our study identified a higher number of partially sirolimus-responsive CHI cases, although the high rate of complications while on this medication limited its potential usefulness.

Conclusion: Sirolimus candidates must be carefully selected given its frequent and potentially lifethreatening side effects. Its use as a short-term, last-resort therapy until normoglycemia is achieved with other agents such as lanreotide could avoid pancreatectomy. Further studies evaluating the use of sirolimus in patients with CHI are required.

Copyright (C) 2019 Endocrine Society

This article has been published under the terms of the Creative Commons Attribution NonCommercial, No-Derivatives License (CC BY-NC-ND; https://creativecommons.org/licenses/by-nc$\mathrm{nd} / 4.0 /)$.

Freeform/Key Words: sirolimus, mTOR inhibitors, hyperinsulinemic hypoglycemia, $A B C C 8$ gene, side effects

\footnotetext{
Abbreviations: BWS, Beckwith-Wiedemann syndrome; CHI, congenital hyperinsulinaemic hypoglycaemia; DM, diabetes mellitus; HI, hyperinsulinemic hypoglycemia; PET, positron emission tomography; PI3K, phosphatidylinositol 3-kinase; mTOR, mammalian target of rapamycin; mTORC, mammalian target of rapamycin complex.
} 
Congenital hyperinsulinemic hypoglycemia (CHI) is characterized by the inappropriate, excessive secretion of insulin from the pancreatic $\beta$-cell and is the most frequent cause of persistent hypoglycemia in infancy [1]. CHI is a heterogeneous disorder with respect to clinical presentation, imaging, histology, and genetics. To date, mutations in at least 10 different genes (ABCC8, KCNJ11, GLUD1, GCK, HADH, SLC16A1, HNF4A, HNF1A, $P M M 2, P G M 1)$ have been reported in the genetic etiology of CHI [2-5]. Mutations in ABCC8 and $K C N J 11$ are associated with severe CHI that is unresponsive to medical treatment with diazoxide and octreotide. There are three main histological types of CHI, each with a specific genetic etiology: focal, diffuse, and atypical [6]. In the past, patients with medically unresponsive forms of CHI were treated with subtotal (95\% to 98\%) pancreatectomy. In 2014, Senniappan et al. [7] reported the use of the mammalian target of rapamycin (mTOR) inhibitors, such as sirolimus, as an alternative therapeutic strategy in CHI patients unresponsive to therapy with diazoxide or octreotide.

Sirolimus (formerly known as rapamycin) inhibits the mTOR pathway, potentially limiting the production of insulin from $\beta$ cells [8]. mTOR is a serine/threonine kinase regulated by phosphatidylinositol 3-kinase (PI3K) that integrates a complex cascade of signals that regulate cell growth, metabolism, proliferation, and survival in response to extracellular nutritional and environmental signals [9]. Although the exact underlying mechanisms are unclear, mTOR-signaling activation has been implicated in the regulation of $\beta$-cell mass, cell proliferation, and size. Integration of genomic, proteomic, and systems biology analysis suggests that the mTOR pathway shows a variable but constant activation and overexpression in acinar cells of patients with CHI [10] and in insulin-producing islet cells [11]. There are $>300$ interactions between mTOR-related molecules and 8 CHI genes (GLUD1, SLC16A1, HADH, KCNJ11, ABCC8, HNF1A, GCK, HNF4A), which were identified by the use of a CHI network [12]. Sirolimus has been shown to have the following actions: (i) inhibition of mTOR complex 1 (mTORC1), which inhibits $\beta$-cell mass; (ii) inactivation of mTORC2 (with prolonged exposure), which induces chronic insulin resistance [13]; (iii) possible reduction in the number of insulin receptors via mTOR inhibition on pancreatic $\beta$ cells, leading to decreased insulin secretion [14]; (iv) in vivo, sirolimus alters the glucosestimulated secretion of insulin [15]; (v) in cultures, sirolimus reduces the number of ductal cells, a potential source of islet cells [15]; and (vi) in mice, sirolimus induces a $50 \%$ decrease in $\beta$-cell mass by apoptosis [16].

Conversely, two publications dismiss the use of mTOR inhibitors in CHI: (i) in islets of two children with diffuse $\mathrm{CHI}$, cell proliferation remained high with no reduction after mTOR inhibitor treatment [17]. The caveat of this study is that both patients had previously not responded to sirolimus and the study was not performed immediately after stopping sirolimus. (ii) An in silico transcriptome array study showed no substantial association between mTOR signaling and the focal form of CHI [17].

Adverse effects of sirolimus include stomatitis [18], increased risk of infection, immunosuppression, abnormalities in renal function, fatigue, pneumonitis, episodes of transient elevation of aminotransferase concentrations [17], and elevation of triglyceride concentrations [7]. These adverse effects are reversible with dose reduction. Studies in kidney transplant recipients [19] have suggested that sirolimus used in the long term may be diabetogenic; this complication was recently published in a patient with CHI [20]. The mechanisms by which sirolimus induces diabetogenic effects may include: (i) impaired $\beta$-cell proliferation by impairing AKT activation and signaling (IGF-1/mTOR/Akt pathway) [13]; (ii) direct $\beta$-cell toxicity; (iii) negative modulation of insulin action in peripheral tissues including skeletal muscle, liver, and white fat; (iv) direct insulin resistance from ectopic triglyceride deposition [18]; and (v) glucose intolerance by upregulation of liver gluconeogenesis [21].

Growing bodies of evidence from CHI patients treated with sirolimus suggest that sirolimus use meets with limited success and carries a greater risk of side effects than any of the standard medications for CHI [17]. Therefore, it must be used with caution in children with severe CHI, and only after discussion with families about its side effects and potential complications [17]. 
The aim of this study was to assess the efficacy of mTOR inhibitors (glycemic control, fasting tolerance, and weaning of supportive medical therapy) and to identify adverse reactions/complications (frequency and severity) related to sirolimus use in a cohort of patients with severe forms of CHI.

\section{Methods}

\section{A. Study Design and Participants}

The current study is a single-center retrospective analysis of data from 22 children with severe CHI, unresponsive to maximum doses of diazoxide and octreotide, who were treated with sirolimus between the years 2013 and 2018. Diagnosis and management in all cases was conducted within the Endocrinology Department of Great Ormond Street Hospital for Children NHS Trust, London, United Kingdom. This series of patients includes the progress of seven patients previously reported in the literature with CHI managed on sirolimus therapy [7, 20, 22, 23]. Other mTOR inhibitors were not used in this study.

Ethical approval had been obtained before the trial of sirolimus in 2014 by Senniappan et al. [7]. Patients were only begun on sirolimus therapy after informed consent was obtained from parents. The protocol for sirolimus use in CHI patients in our center had been elaborated in combination with our pharmacy. The dose of sirolimus was gradually increased every 4 to 5 days based on blood glucose concentrations, sirolimus plasma concentrations, and side effects. If blood glucose concentrations were stable, the dose of sirolimus was not increased (even if plasma concentrations were below the target range) to avoid possible complications. Complete response to sirolimus was defined as glycemic control achieved exclusively with sirolimus, partial response as glycemic stability obtained with sirolimus concomitantly with another CHI agent, and no response as absent glycemic improvement despite combination of sirolimus with other CHI medications. Glycemic control in individuals with $\mathrm{CHI}$ is defined as plasma glucose concentrations maintained between 3.5 and $7.0 \mathrm{mmol} / \mathrm{L}$ with avoidance of hypoglycemia $(<3.5 \mathrm{mmol} / \mathrm{L})$ episodes, along with the capacity to extend the fasting time (approaching or achieving age-appropriate fasting length) without developing hypoglycemia while generating an increase in ketone bodies and free fatty acids. Patients did not receive any live vaccinations while on sirolimus.

The data collection included the following aspects: characteristics of patients with CHI (presentation of CHI), onset of sirolimus therapy (concomitant management and sirolimus dose and plasma concentrations, duration of treatment), side effects while on sirolimus therapy (type of complication, dose, and plasma concentrations of sirolimus at the time), and eventual patient management (medication \pm feed regimen). Data are presented as median (range), where range includes maximum to minimum values. Pathology images were obtained from the Histopathology Department of Great Ormond Street Hospital for Children NHS Trust after pancreatectomy in children who had previously been treated with sirolimus.

Previous publications on the use of mTOR inhibitors in children with CHI were identified in PubMed (last search performed 9 August 2018); results were summarized in this study.

\section{Results}

Fifteen publications of cases of CHI where mTOR inhibitors had been used were identified. These include a total of 31 children treated in countries in Europe, Middle East, and South East Asia. Nineteen of 31 (61.3\%) patients have been reported to have a positive glycemic response to mTOR inhibitors in monotherapy or combined with another CHI medication. Any complication of any nature and severity while on mTOR inhibitor therapy has been reported in 26 of 31 (83.8\%). Table 1 outlines these publications and characteristics related to the use of mTOR inhibitors.

The characteristics of the $22 \mathrm{CHI}$ patients included in our study are summarized in Table 2. A total of $90.9 \%$ of patients (20/22) were diagnosed with CHI within the first month of 


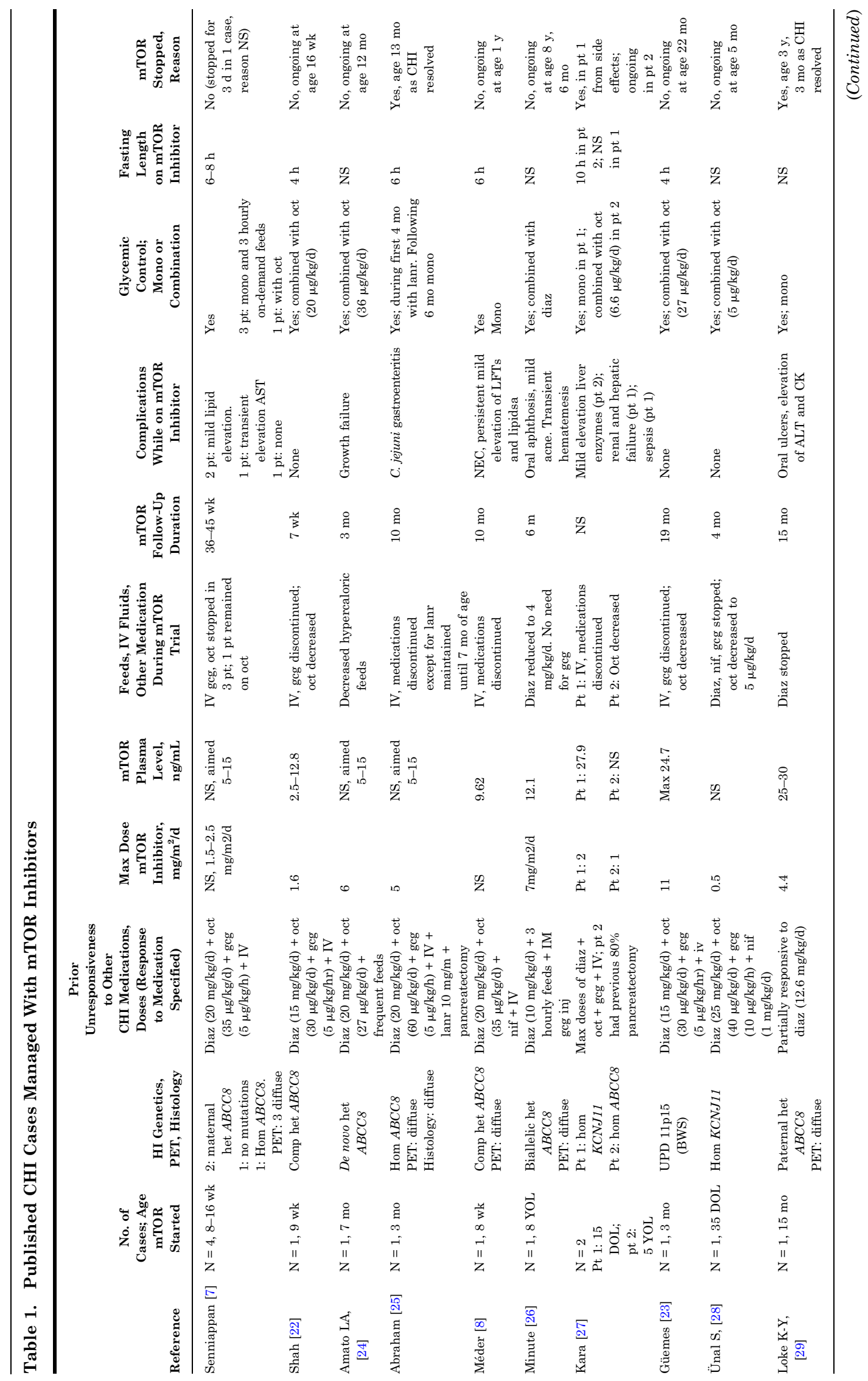




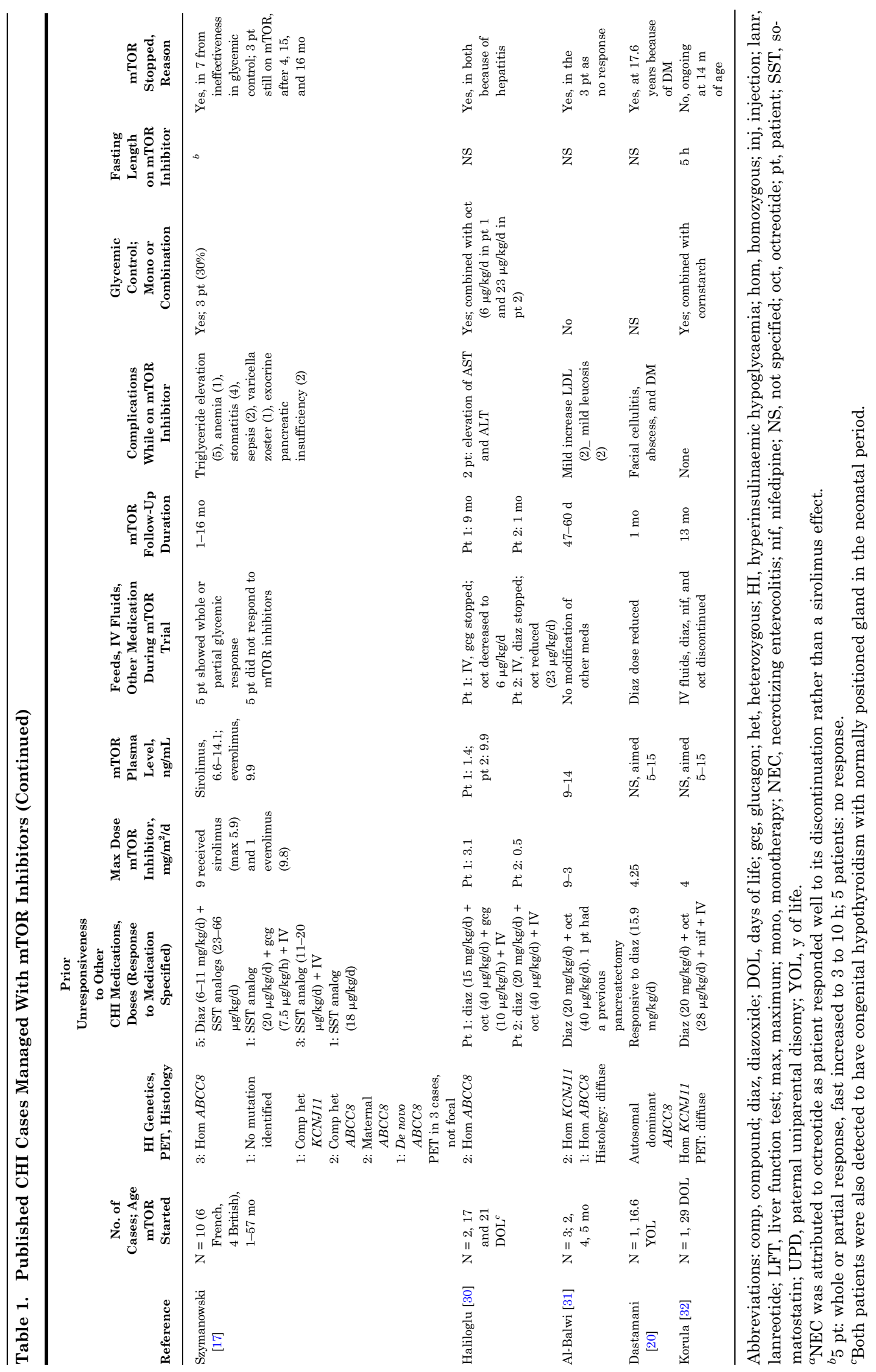


Table 2. Characteristics of Patients With CHI In This Study

\begin{tabular}{|c|c|}
\hline \multicolumn{2}{|l|}{ CHI Patient Characteristics } \\
\hline Sex & 14 Females, 8 Males \\
\hline Weeks of gestation, median (range) & $38(33-40.5)$ \\
\hline Birth weight, median (range) & $4050 \mathrm{~g}(2138-5300)$ \\
\hline Birth weight, median (range), SDS & 1.71 SDS $(-0.65$ to +3.81$)$ \\
\hline \multirow[t]{3}{*}{ Perinatal CHI risk factors } & Gestational diabetes (2) \\
\hline & Mother had DM type 2 (1) \\
\hline & None (19) \\
\hline \multirow[t]{4}{*}{ Age at presentation } & Within first $2 \mathrm{~d}$ of life (19) \\
\hline & Within $30 \mathrm{~d}$ of life (1) \\
\hline & At 13 mo (hypoglycemia episodes undiagnosed during the first days of life) (1) \\
\hline & At $18 \mathrm{mo}(1)$ \\
\hline \multirow[t]{5}{*}{ Genetics } & $\begin{array}{l}15 \text { ABCC } 8 \text { mutations: } 4 \text { homozygous } A B C C 8,5 \text { Compound heterozygous } \\
A B C C 8,6 \text { Autosomal dominant heterozygous } A B C C 8 \text { ( } 2 \text { maternal, } 3 \\
\text { paternal, } 1 \text { de novo) }\end{array}$ \\
\hline & 4 Negative genetics \\
\hline & $1 G C K$ activating mutation \\
\hline & $1 \mathrm{BWS}$ \\
\hline & 1 Rubinstein-Taybi syndrome \\
\hline \multirow[t]{3}{*}{ Syndrome } & $1 \mathrm{BWS}$ \\
\hline & 1 Rubinstein-Taybi \\
\hline & 1 Suspected BWS; genetics negative \\
\hline \multirow{3}{*}{ PET scan report } & Diffuse (14) \\
\hline & Focal: 1 in pancreatic head, 1 neck of pancreas \\
\hline & Not performed (6) \\
\hline
\end{tabular}

Abbreviation: SDS, standard deviation score.

life, with 2 cases diagnosed during the second year of life. An $A B C C 8$ mutation was identified in $68.2 \%(15 / 22)$ of the patients, whereas $13.6 \%(3 / 22)$ had other genetic findings associated with CHI. Only $18.2 \%$ (4/22) had no genetic findings related to CHI. 18F-fluoro-L-dihydroxyphenylalanine positron emission tomography (PET) scan revealed diffuse forms of CHI in $63.6 \%$ (14/22) and focal forms in $9.1 \%$ (2/22), whereas no imaging was performed in $27.3 \%$ (6/22). Three patients had a pancreatectomy before commencing sirolimus (one had negative CHI genetics, one was a compound $A B C C 8$ heterozygote, and one had a $G C K$ mutation).

The onset of management with sirolimus is shown in Table 3. At the time sirolimus was commenced, 1 patient was on no CHI medications, another was on cornstarch, 10 were receiving $1 \mathrm{CHI}$ medication, and 10 were on $\geq 2 \mathrm{CHI}$ medications. Partial/total response was observed in $95.5 \%$ (21/22) patients in our cohort, of which 1 showed total response and 20 partial response. A total of $4.5 \%$ (1/22) were unresponsive; $23.8 \%(5 / 21)$ of the partially/fully responsive patients had compound heterozygous $A B C C 8$ mutations and $23.8 \%$ (5/21) had heterozygous ABCC8 mutation.

Complications detected while on sirolimus are summarized in Table 4. In those who had an infection, a bacterial etiology was identified in $64.7 \%$ (11/17) of cases. Of note, a 16-year-old female with $\mathrm{CHI}$ resulting from a dominant $A B C C 8$ gene mutation developed diabetes mellitus (DM) when clarithromycin was added to sirolimus [20]. Her dominant ABCC8 mutation predisposes to DM (her mother with the same mutation had also developed DM), and there could have been a drug-drug interaction that potentiated the diabetogenic effect. The eventual management strategy required to achieve normoglycemia, whether on sirolimus or other medication/surgery, is shown in Table 5. Five of 22 patients $(22.7 \%)$ remain on weaning doses of sirolimus requiring intensive feeding regimens (4 are on overnight continuous feeds, with added $10 \%$ carbohydrate content). The three patients that had a pancreatectomy before commencing sirolimus therapy all showed partial responses, and are currently managed on diazoxide $(n=2)$ and octreotide $(n=1)$, combined with continuous overnight feeds. Of note, four patients received sirolimus for a range of 13 months to 2.5 years, 
Table 3. Onset of Management With Sirolimus in Patients With CHI

\begin{tabular}{|c|c|}
\hline \multicolumn{2}{|l|}{ Onset of Sirolimus Therapy } \\
\hline Age (mo) sirolimus started, median (range) & 3.87 (1.5-198), 10 started during first trimester of life \\
\hline Weight at sirolimus start, median (range), SDS & $0.81 \mathrm{~g}(0.05-3.31)$ \\
\hline Starting dose of sirolimus, median (range), $\mathrm{mg} / \mathrm{m}^{2} / \mathrm{d}$ & $0.96(0.5-4)$ \\
\hline Total number of mo receiving sirolimus, median (range) & $21.5(3-59)^{a}$ \\
\hline Starting level of sirolimus, median (range), $\mathrm{ng} / \mathrm{mL}$ & $4.7(2-14.5)$ \\
\hline \multirow[t]{3}{*}{ Other medications at time of starting sirolimus } & Glucagon infusion $(5-10 \mu \mathrm{g} / \mathrm{kg} / \mathrm{h}): 10$ patients \\
\hline & Diazoxide $(6.2-18 \mathrm{mg} / \mathrm{kg} / \mathrm{d}): 5$ patients \\
\hline & Octreotide $(20-40 \mu \mathrm{g} / \mathrm{kg} / \mathrm{d}): 17$ patients \\
\hline \multirow[t]{3}{*}{ IV and feeds while on sirolimus } & $8 \mathrm{IV}$ dextrose with/without continuous feeds \\
\hline & 6 continuous enteral feeds exclusively \\
\hline & 8 frequent feeds exclusively \\
\hline Maximum dose sirolimus, median (range), $\mathrm{mg} / \mathrm{m}^{2} / \mathrm{d}$ & $6.5(1.76-17)$ \\
\hline Level of sirolimus at maximum dose, median (range), ng/mL & $16.35(5.1-46.1)$ \\
\hline \multirow[t]{3}{*}{ Response to sirolimus } & Partial response: 20 (91\%) \\
\hline & Complete response: $1(4.5 \%)$ \\
\hline & Unresponsive: $1(4.5 \%)$ \\
\hline \multirow[t]{7}{*}{ Genetics vs response } & Partial response: 5 compound heterozygous $A B C C 8$; \\
\hline & 5 autosomal dominant heterozygous $A B C C 8 ; 3$ \\
\hline & homozygous $A B C C 8 ; 4$ negative genetics for known \\
\hline & CHI genes; 1 BWS; 1 Rubinstein-Taybi syndrome; \\
\hline & 1 GCK mutation \\
\hline & Complete response: 1 autosomal dominant \\
\hline & $\begin{array}{l}\text { neterozygous ABCC8 } \\
\text { Unresponsive: } 1 \text { homozygous } A B C C 8\end{array}$ \\
\hline
\end{tabular}

${ }^{a}$ Two stopped it transiently ( 1 from concerns for infection/parainfluenza, decision taken by medical team; 1 unspecified infections, decision taken by parents) and restarted; total number of months on sirolimus included.

were then switched to lanreotide, and currently remain with good glycemic control having avoided a pancreatectomy; in 2 of these cases, the reason for stopping sirolimus was responsiveness to lanreotide, whereas in the rest it was due to infection. A fifth patient remains on sirolimus and lanreotide, having also avoided surgery. Two patients with compound heterozygous $A B C C 8$ mutations, classified as partially responsive to sirolimus, were initially able to fast for 8 hours; over time, their fasting tolerance dropped to 2 to 3 hours, at which point sirolimus was stopped.

Histopathology of the pancreas in four patients after the use of sirolimus is shown in Figure 1. The histopathology of the excised pancreatic tissue showed some variability in the amount of fibrous tissue within pancreas, but no greater than in the normal pancreas. Two patients had focal disease and two had diffuse disease. There were no other specific features identified. Pancreatectomy took place 4 to 24 months after sirolimus treatment. The reasons for stopping sirolimus and performing surgery were lesionectomy of focal form in one patient, no response to sirolimus in one, and side effects from sirolimus in two.

\section{Discussion}

To the best of our knowledge, this study reports the largest cohort of patients with CHI treated with sirolimus at a single center, representing a 5-year experience of this therapy. Given the controversies surrounding the usefulness, variable therapeutic success, and risks of this medication for CHI, previous case publications were reviewed. Overall, published cases show glycemic improvement, but at the expense of frequent side effects. The caution exerted when comparing our manuscript with previous case reports relies on the diverse nature of such case reports, given the rarity of $\mathrm{CHI}$ and, moreover, the use of mTOR inhibitors for this indication. These reports include small number of subjects, of different ages, with 
Table 4. Complications Detected While on Sirolimus Treatment

\begin{tabular}{|c|c|}
\hline \multicolumn{2}{|l|}{ Side Effects } \\
\hline Side effects to sirolimus & $\begin{array}{l}19(86.4 \%): \text { Yes } \\
3(13.6 \%): \text { No }\end{array}$ \\
\hline $\begin{array}{l}\text { Time between onset of sirolimus and side effects, } \\
\text { median (range), mo }\end{array}$ & $13(1-52)$ \\
\hline $\begin{array}{l}\text { Dose sirolimus when side effect detected, } \\
\text { median (range), } \mathrm{mg} / \mathrm{m}^{2} / \mathrm{d}\end{array}$ & $3.1(0.5-17.4)$ \\
\hline $\begin{array}{l}\text { Levels of sirolimus when developed side effects, } \\
\text { median (range) }, \mathrm{ng} / \mathrm{mL}\end{array}$ & $13.8(2-65.6)$ \\
\hline Infection & $\begin{array}{l}\text { Yes (17); } 11 \text { bacterial infections ( } 1 \text { osteomyelitis, } 2 \text { abscess, } \\
1 \text { tonsillitis, } 1 \text { UTI, } 3 \text { sepsis, } 3 \text { PEG site infection [2 progressed } \\
\text { to cellulitis]; } 2 \text { viral + bacterial infection ( } 1 \text { influenza A + UTI; } \\
1 \text { chickenpox + cellulitis); } 2 \text { viral infections ( } 1 \text { EBV, } \\
1 \text { chickenpox); } 2 \text { uncertain etiology ( } 1 \text { recurrent UTI, } \\
1 \text { self-resolved fever) } \\
\text { No (5) }\end{array}$ \\
\hline Other side effects & $\begin{array}{l}\text { Diarrhea ( } 3 ; 1 \text { with blood in stools) } \\
\text { Hyperglycemia (2) } \\
\text { Improved after stopping sirolimus (1) } \\
\text { Developed DM (1) [20] } \\
\text { Difficult healing after extravasation injury (1) }\end{array}$ \\
\hline Reasons sirolimus was stopped & $\begin{array}{l}\text { Infection (12) } \\
\text { Other (5) } \\
\text { Hyperglycemia (2) } \\
\text { Responded to lanreotide (2) } \\
\text { Persistent diarrhea with increased calprotectin (1) } \\
\text { Weaned off until stopped because of concerns for long-term } \\
\quad \text { side effects (1) } \\
\text { Remains on it (1) }\end{array}$ \\
\hline
\end{tabular}

Abbreviations: DM, diabetes mellitus; EBV, Epstein-Barr virus; PEG, percutaneous endoscopic gastrostomy; UTI, urinary tract infection.

various genetic makeup findings, the use of diverse concomitant treatments at different doses, the definition of response to medication, and documentation of effects. The caveat is that most case reports do not clearly state a definition of positive glycemic response to mTOR inhibitors, but rather indicate if each patient was able to come off IV glucose and discharged home on monotherapy or combination of CHI medications maintaining stable glucose concentrations. Critique could also be made to a certain extent on the preciseness of the criteria for responsiveness in the current study; however, the rarity of this challenging disorder combined with numerous management variables (IV dextrose infusion, continuous gastric feeding, glucagon infusion) render it difficult to establish more rigorous targets. Publication bias should be taken into account, because it is possible that trials with an unimpressive outcome to this drug may have been unpublished.

mTOR inhibitors have proven their efficacy to control excessive insulin release in insulinomas [33], where the mTOR pathway is abnormally activated. In an attempt to avoid extensive pancreatectomy in children with severe diffuse CHI, which eventually renders children diabetic with pancreatic exocrine deficiency, and is, in some cases, only partially curative with an ongoing need for medication [34], sirolimus was promoted as a promising therapeutic agent by Senniappan et al. [7].

The patients reported in this study, in concordance with those in the literature, had extremely severe forms of $\mathrm{CHI}$ that had already failed to respond to medical treatment with maximum doses of diazoxide and octreotide and, in some, that was also unresponsive to glucagon and nifedipine. This highlights the challenges inherent in the management of these patients. The mTOR pathway has been shown to have a variable but constant activation and overexpression in acinar cells of patients with CHI [10] and in insulin-producing islet cells 
Table 5. Eventual Management of Patients With CHI

\section{Eventual Management}

Pancreatectomy

Twenty-one patients that stopped sirolimus responded to:

One patient that remains on sirolimus
After sirolimus start (3 permanently stopped sirolimus, 1 restarted sirolimus after operation): 4

Prior sirolimus start: 3

No pancreatectomy: 15

Pancreatectomy + diazoxide (3.8-10.2 mg/kg/d) + feeds on-demand: 2

Pancreatectomy + octreotide $(20-39.3 \mu \mathrm{g} / \mathrm{kg} / \mathrm{d})+$ continuous overnight feeds 10\%-16\% CHO: 2

Pancreatectomy + octreotide $(13 \mu \mathrm{g} / \mathrm{kg} / \mathrm{d}): 1$

Pancreatectomy + lanreotide (30 mg/7 wk) + on-demand feeds: 1

Pancreatectomy + on-demand feeds: 1

Octreotide $(40 \mu \mathrm{g} / \mathrm{kg} / \mathrm{d})+$ continuous overnight feeds 10\%-16\% CHO: 2

Octreotide $(36 \mu \mathrm{g} / \mathrm{kg} / \mathrm{d})+$ continuous overnight feeds 10\% CHO: 1

Octreotide $(32 \mu \mathrm{g} / \mathrm{kg} / \mathrm{d})+$ continuous overnight feeds 18\% CHO: 1

Octreotide $(24.6 \mu \mathrm{g} / \mathrm{kg} / \mathrm{d})+$ on-demand feeds: 1

Octreotide $(20 \mu \mathrm{g} / \mathrm{kg} / \mathrm{d})+$ continuous overnight feeds 10\% CHO: 1

Octreotide $(16 \mu \mathrm{g} / \mathrm{kg} / \mathrm{d})+$ continuous overnight feeds 10\% CHO: 1

Lanreotide $(30 \mathrm{mg} / 4 \mathrm{wk})+$ on-demand feeds: 1

Lanreotide $(60 \mathrm{mg} / 3 \mathrm{wk})+$ continuous overnight feeds: 1

Lanreotide $(60 \mathrm{mg} / 4 \mathrm{wk})+3 \mathrm{hh}$ feeds: 1

Overnight continuous feeds: 1

Frequent feeds: 1

Metformin because of DM: $1^{a}$

Fasting capacity while on sirolimus (h): median (range): 8 (3-18)

No episodes of hypoglycemia at all: 2

Genetics:

Autosomal dominant heterozygous ABCC8: 6

$A B C C 8$ compound heterozygous: 5

$A B C C 8$ homozygous: 4

Negative genetics for known CHI genes: 4

GCK: 1

BWS: 1

Rubinstein-Taybi syndrome: 1

Lanreotide $(60 \mathrm{mg} / 4 \mathrm{wk})$, sirolimus $\left(3.2 \mathrm{mg} / \mathrm{m}^{2} / \mathrm{d}\right.$; level $\left.2 \mathrm{ng} / \mathrm{L}\right)+$ continuous overnight feeds 10\% CHO: 1

Fasting capacity while on sirolimus (h): 6

Genetics: ABCC 8 homozygous: 1

Abbreviation: CHO, carbohydrate content.

${ }^{a}$ As published in Dastamani A et al., [20]

[11]. Conversely, a study analyzed pancreatic tissue from two sirolimus-unresponsive patients with $\mathrm{CHI}$ in which there was no reduction in cell proliferation [17]. An interpretation to this could be that the resistance to sirolimus might be due to the fact that the cell proliferation could be mTOR-independent. The histopathology of four pancreatic tissue samples examined in this study did not show important changes after the use of sirolimus; however, one possible criticism of the study may lie in the diverse time postsirolimus use and the variability in the pathological analysis of tissue.

Since the first publication of sirolimus use for CHI, 15 case reports have followed that are quite diverse in terms of their characteristics. Sirolimus has been mainly used in infants but also in an 8-year-old boy [26]. Most children harbor ABCC8 or KCNJ11 mutations in homozygosity or compound heterozygosity, but sirolimus has also been successfully used in a patient with Beckwith-Wiedemann syndrome (BWS) [23]. The majority of patients in case studies received sirolimus, but one received everolimus [17], which has a different half-life and plasma level range. Comparison between studies with surgically naïve patients and other patients with previous pancreatectomy $[25,27,31]$ can also add a further layer of complexity. 

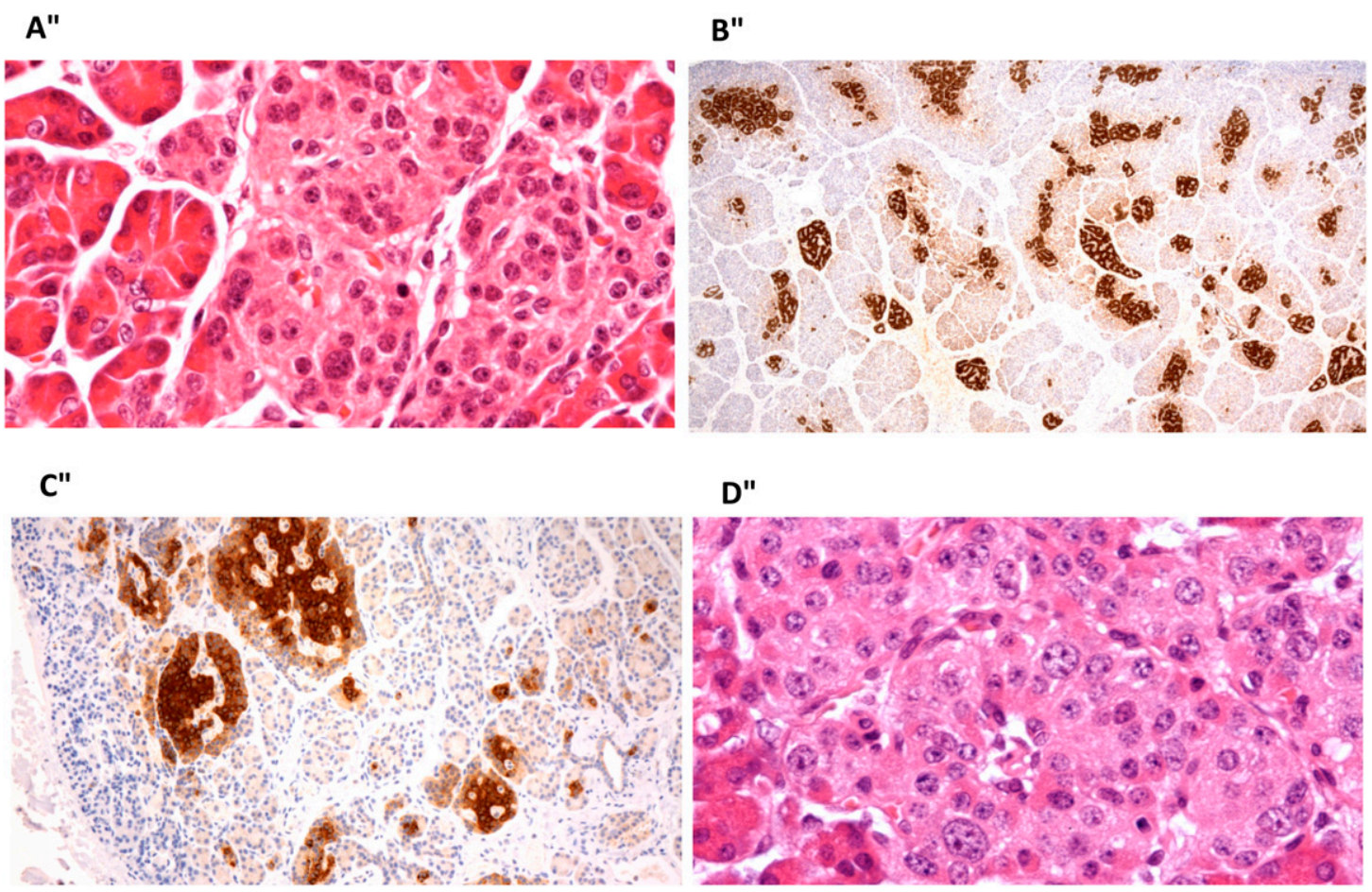

Figure 1. Histopathology of pancreas after sirolimus use. (A) Patient with diffuse CHI resulting from a homozygous $A B C C 8$ mutation, 4 mo after sirolimus treatment. High-power view of an islet showing scattered enlarged islet-cell nuclei. This change was present in islets throughout the tissue, in keeping with diffuse disease. (B) Patient with focal CHI resulting from paternal compound heterozygous $A B C C 8$ mutation, 12 mo after sirolimus. There is an increase in islet-cell tissue with strong proinsulin staining. There was no diffuse islet-cell nuclear enlargement. The appearances suggest an atypical focal form of the disease. (C) Patient with focal CHI resulting from a paternal compound heterozygous $A B C C 8$ mutation, 21 mo after sirolimus use. The image shows enlarged and clustered islets that stain strongly for proinsulin, in keeping with focal disease. (D) Patient with diffuse CHI resulting from homozygous $A B C C 8$ mutation, 24 mo after sirolimus. There were scattered enlarged islet-cell nuclei throughout the tissue, indicating diffuse disease. Images taken with Nikon Eclipse E600 microscope; (A, D) Stained with hematoxylin and eosin; (B, C) stained with antibody to proinsulin. Original magnification: $(A) \times 400$, (B) $\times 20$, (C) $\times 100$, (D) $\times 400$.

Although sirolimus has been mainly used in diffuse forms of CHI, in our study, this dual mTORC1/mTORC2 inhibitor agent was also used in two patients with $18 \mathrm{~F}$-fluoro-LdihydroxyphenylalaninePET/CT scans compatible with focal disease. Both patients were heterozygous for a paternally inherited $A B C C 8$ mutation; one did respond to sirolimus and had no side effects, and the other is currently still on sirolimus and octreotide at the age of 15 months with the complication of frequent skin infections around the gastrostomy site.

In our study, as in most case publications, sirolimus was started in combination with other CHI medications to counter the variable but constant activation of the mTOR pathway in CHI [12]. Despite the wide range of dose used, aiming to maintain medication blood concentrations within a therapeutic window and minimizing side effects, the median dose range is nevertheless higher than those reported in the literature. The higher doses may perhaps have influenced our higher rate of success, because partial/total response was observed in $95.5 \%$ of our cohort (the majority showing a partial response). This is a striking difference from the results published by Szymanowski et al. [17], in which the mTOR inhibitor was found to be clinically useful in 30\% of patients in whom it was used. These authors also suggest that patients with dominantly inherited mutations in $A B C C 8$ have a higher rate of response [17], concurring with the findings from another study [11]. In our study, heterozygous mutations and compound heterozygous mutations in $A B C C 8$ were more likely to have a partial/total 
response, with one case with de novo heterozygous $A B C C 8$ mutation achieving glycemic control on sirolimus monotherapy and avoiding surgery. We speculate that it seems unlikely that compound heterozygosity per se is affecting the response, but rather that the good outcome observed with compound heterozygosity may reflect the functional impact of the two mutations. Our patient with BWS previously reported as sirolimus-responsive in combination with octreotide [23] was switched at age 23 months to lanreotide, to which a good glycemic response was obtained.

Some of the published CHI cases on sirolimus have been shown to fast for up to 8 hours without developing hypoglycemia [7]. In our study, children on sirolimus showed improvement in their fast tolerance at the start of the treatment, and fasting time ranged from 3 to 8 hours on their latest fast provocation test. Two patients seemed to show a lower fasting capacity over time, perhaps suggesting that it may eventually become less effective in terms of glycemic control. Additionally, one publication reported increased quality of life since sirolimus helped to stabilize glycemia in a patient [26]. Of interesting, of the 17 patients that stopped sirolimus, only 4 required pancreatectomy; the rest were managed medically \pm feeds (excluding the patient that developed DM). This could indicate a use for sirolimus for short periods, thereby avoiding near-total pancreatectomy and its long-term adverse effects. Nevertheless, with such an approach, we recommend close monitoring of sirolimus trough concentrations and its side effects.

Cellular signaling studies in dermal fibroblasts from one patient with severe nonketotic hypoinsulinemic hypoglycemia resulting from mosaic genetic activation of class 1A PI3K (insulin signaling pathway) showed that sirolimus potently suppressed the increased basal AKT phosphorylation at very low doses (1.1 to $2.2 \mathrm{ng} / \mathrm{mL}$ ). This offers mTOR inhibitors (or potentially PI3K inhibitors) a future therapeutic role in this rare form of hypoketotic hypoglycemia [35].

As in most studies using sirolimus in CHI patients, we also aimed for trough concentrations of 5 to $15 \mathrm{ng} / \mathrm{mL}$. Interestingly, a case report stated that in a patient with CHI, the target was increased to that used in transplant patients, without any major side effects, although no glycemic response was achieved [31]. Postrenal transplant children seem to tolerate well doses of sirolimus of around $6 \mathrm{mg} / \mathrm{m}^{2} / \mathrm{d}$ (target concentration 10 to $20 \mathrm{ng} / \mathrm{mL}$ ) [36]. In our experience, sirolimus plasma concentrations were of limited use to titrate drug dose because their reproducibility was low given their dependence on sirolimus enteral absorption rate. This is why dose titration was based on maintenance of euglycemia (even if sirolimus concentrations were below the cutoff value) with avoidance of side effects. Reducing the dose, as observed in other studies, reverses side effects. Oral mucositis is frequent and can be minimized by rinsing the mouth with water or juice after the dose. However, a report on three children with CHI who received sirolimus doses as high as $35 \mathrm{mg} / \mathrm{m}^{2} / \mathrm{d}$ reported no major side effects or infections [31].

Our study, with a wide range of trough concentrations of sirolimus, has the same rate of complications as collected in the case reports from the literature $(86.4 \%$ vs $83.8 \%)$, which is not to be taken lightly. These complications can appear early, or after many months, and mainly involve infections of varying degrees of severity, in agreement with the literature. Infection is the main cause of discontinuation of sirolimus. Autosomal dominant ABCC 8 gene mutations causing CHI in infancy are known, in some cases, to be linked to DM at a later stage of life. A published case illustrates how sirolimus (combined with clarithromycin) may have precipitated the onset of diabetes [20].

Because the natural history of the condition is to get milder over time with slow progressive $\beta$-cell apoptosis, in some cases sirolimus would only be required for a short period, avoiding possible long-term consequences. For other cases, sirolimus could keep some children stable until they are older and are then switched to another treatment (e.g., lanreotide) to avoid pancreatectomy. This strategy worked for four of our patients. Similarly, Haliloglu et al. [30] had reported 2 patients responsive to sirolimus combined with octreotide, in which the former drug was discontinued because hepatitis, and both were managed on octreotide-LAR after the age of 7 months. Sirolimus may be a hazardous drug, however; even 
after a $95 \%$ pancreatectomy, $60 \%$ of patients will remain with profound hypoglycemia [37] and therefore remain at risk for severe brain injury. Discussion with parents must therefore include the variable response and potential side effects of sirolimus as well as their preferred choice of treatment.

It is difficult to confirm causality of complications for every case, given that these infants need central access, admitted in the hospital for long periods, usually on a combination of medications, and may have other associated comorbidities; it is not uncommon for them to develop infections and other side effects. Because complications mainly developed while combined with other medications, the latter may also be held responsible of some of these. For instance, the CHI case published by Korula et al. [32] had a nonfermenting gram-negative bacilli sepsis before sirolimus treatment and had not had any infections or side effects in the 14 months of treatment on sirolimus. Further studies analyzing the long-term use of sirolimus in children with CHI are needed. Also, the response of children with other CHI genetic mutations to sirolimus needs to be investigated.

Although the potential role for mTOR inhibitors in certain CHI cases cannot be ignored, a thoughtful decision-making process regarding the optimal therapy for patients with severe medically unresponsive CHI must be undertaken, balancing potential benefit vs risks. The latter are common and potentially life-threatening; in view of these concerns, we would suggest the use of mTOR inhibitors as a last-resort therapy for extremely severe CHI cases unresponsive to conventional CHI medications, for curtailed periods with close monitoring, with the caveat that plasma concentrations are of limited use given their variability.

\section{Research in Context}

\section{A. Evidence Before This Study}

mTOR inhibitors, in particular sirolimus, have been used in the past 5 years in children with severe forms of congenital hyperinsulinism (CHI) that do not respond to maximal doses of diazoxide and octreotide. Because CHI is a rare disease, a PubMed search (in English, Spanish, and Greek) was performed, and characteristics of the 15 publications reporting cases in which $\mathrm{mTOR}$ inhibitors were used for this condition were analyzed. Reported response to sirolimus in the literature is variable, but with a high rate of adverse effects.

\section{B. Added Value of This Study}

Our study, to the best of our knowledge, reports the largest series of CHI patients treated with sirolimus, with the longest follow-up duration. We have compared our findings with those previously published. Our study describes a higher number of CHI cases that are partially sirolimus-responsive and a similar high rate of complications while on this medication.

\section{Implications of All the Available Evidence}

Given the frequent and potentially severe complications while on this medication, candidates for this therapy should be meticulously selected. Transient use of sirolimus, until achievement of euglycemia on therapies such as lanreotide, could be a future approach to avoid pancreatectomy.

\section{Acknowledgments}

The authors express their gratitude to the families of the patients involved in this study. Additionally, the authors extend their acknowledgment to Great Ormond Street Hospital Children's Charity, UK CHI Parents Charity, and Great Ormond Street Hospital Biomedical Research Centre.

Financial Support: This work was supported by the Great Ormond Street Hospital Children's Charity, UK CHI Parents Charity, and Great Ormond Street Hospital Biomedical Research Centre. 
Current Affiliation: G.M.'s current affiliation is the Endocrinology Service, Hospital Infantil Universitario Niño Jesús, 28009 Madrid, Spain.

Correspondence: Pratik Shah, PhD, Great Ormond Street Hospital for Children and UCL Great Ormond Street Institute of Child Health, Great Ormond Street, London WC1N 3JH, United Kingdom. E-mail: pratik.shah@gosh.nhs.uk.

Disclosure Summary: The authors have nothing to disclose.

\section{References and Notes}

1. Senniappan S, Shanti B, James C, Hussain K. Hyperinsulinaemic hypoglycaemia: genetic mechanisms, diagnosis and management. J Inherit Metab Dis. 2012;35(4):589-601.

2. Flanagan SE, Kapoor RR, Hussain K. Genetics of congenital hyperinsulinemic hypoglycemia. Semin Pediatr Surg. 2011;20(1):13-17.

3. Cabezas OR, Flanagan SE, Stanescu H, García-Martínez E, Caswell R, Lango-Allen H, Antón-Gamero M, Argente J, Bussell AM, Brandli A, Cheshire C, Crowne E, Dumitriu S, Drynda R, Hamilton-Shield JP, Hayes W, Hofherr A, Iancu D, Issler N, Jefferies C, Jones P, Johnson M, Kesselheim A, Klootwijk E, Koettgen M, Lewis W, Martos JM, Mozere M, Norman J, Patel V, Parrish A, Pérez-Cerdá C, Pozo J, Rahman SA, Sebire N, Tekman M, Turnpenny PD, Hoff WV, Viering DHHM, Weedon MN, Wilson P, Guay-Woodford L, Kleta R, Hussain K, Ellard S, Bockenhauer D. Polycystic kidney disease with hyperinsulinemic hypoglycemia caused by a promoter mutation in phosphomannomutase 2. J Am Soc Nephrol. 2017;28(8):2529-2539.

4. Pinney SE, Ganapathy K, Bradfield J, Stokes D, Sasson A, Mackiewicz K, Boodhansingh K, Hughes N, Becker S, Givler S, Macmullen C, Monos D, Ganguly A, Hakonarson H, Stanley CA. Dominant form of congenital hyperinsulinism maps to HK1 region on 10q. Horm Res Paediatr. 2013;80(1):18-27.

5. Tegtmeyer LC, Rust S, van Scherpenzeel M, Ng BG, Losfeld ME, Timal S, Raymond K, He P, Ichikawa M, Veltman J, Huijben K, Shin YS, Sharma V, Adamowicz M, Lammens M, Reunert J, Witten A, Schrapers E, Matthijs G, Jaeken J, Rymen D, Stojkovic T, Laforêt P, Petit F, Aumaître O, Czarnowska E, Piraud M, Podskarbi T, Stanley CA, Matalon R, Burda P, Seyyedi S, Debus V, Socha P, SykutCegielska J, van Spronsen F, de Meirleir L, Vajro P, DeClue T, Ficicioglu C, Wada Y, Wevers RA, Vanderschaeghe D, Callewaert N, Fingerhut R, van Schaftingen E, Freeze HH, Morava E, Lefeber DJ, Marquardt T. Multiple phenotypes in phosphoglucomutase 1 deficiency. $N$ Engl J Med. 2014;370(6): 533-542.

6. Sempoux C, Capito C, Bellanné-Chantelot C, Verkarre V, de Lonlay P, Aigrain Y, Fekete C, Guiot Y, Rahier J. Morphological mosaicism of the pancreatic islets: a novel anatomopathological form of persistent hyperinsulinemic hypoglycemia of infancy. J Clin Endocrinol Metab. 2011;96(12): 3785-3793.

7. Senniappan S, Alexandrescu S, Tatevian N, Shah P, Arya V, Flanagan S, Ellard S, Rampling D, Ashworth M, Brown RE, Hussain K. Sirolimus therapy in infants with severe hyperinsulinemic hypoglycemia. N Engl J Med. 2014;370(12):1131-1137.

8. Méder Ü, Bokodi G, Balogh L, Körner A, Szabó M, Pruhova S, Szabó AJ. Severe hyperinsulinemic hypoglycemia in a neonate: response to sirolimus therapy. Pediatrics. 2015;136(5):e1369-e1372.

9. Kwon G, Marshall CA, Pappan KL, Remedi MS, McDaniel ML. Signaling elements involved in the metabolic regulation of mTOR by nutrients, incretins, and growth factors in islets. Diabetes. 2004; 53(Suppl 3):S225-S232.

10. Alexandrescu S, Tatevian N, Olutoye O, Brown RE. Persistent hyperinsulinemic hypoglycemia of infancy: constitutive activation of the mTOR pathway with associated exocrine-islet transdifferentiation and therapeutic implications. Int J Clin Exp Pathol. 2010;3(7):691-705.

11. Senniappan SBR, Hussain K. Genomic and morphoproteomic correlates implicate the IGF-1/mTOR/ Akt pathway in the pathogenesis of diffuse congenital hyperinsulinism. Int J Clin Exp Pathol. 2016; 9(2):548-562.

12. Brown RE, Senniappan S, Hussain K, McGuire MF. Morphoproteomics and biomedical analytics coincide with clinical outcomes in supporting a constant but variable role for the mTOR pathway in the biology of congenital hyperinsulinism of infancy. Orphanet J Rare Dis. 2017;12(1):181.

13. Sarbassov DD, Ali SM, Sengupta S, Sheen JH, Hsu PP, Bagley AF, Markhard AL, Sabatini DM. Prolonged rapamycin treatment inhibits mTORC2 assembly and Akt/PKB. Mol Cell. 2006;22(2): $159-168$.

14. Leibiger IB, Leibiger B, Moede T, Berggren PO. Exocytosis of insulin promotes insulin gene transcription via the insulin receptor/PI-3 kinase/p70 s6 kinase and CaM kinase pathways. Mol Cell. 1998; 1(6):933-938. 
15. Bussiere CT, Lakey JR, Shapiro AM, Korbutt GS. The impact of the mTOR inhibitor sirolimus on the proliferation and function of pancreatic islets and ductal cells. Diabetologia. 2006;49(10):2341-2349.

16. Fraenkel M, Ketzinel-Gilad M, Ariav Y, Pappo O, Karaca M, Castel J, Berthault MF, Magnan C, Cerasi E, Kaiser N, Leibowitz G. mTOR inhibition by rapamycin prevents beta-cell adaptation to hyperglycemia and exacerbates the metabolic state in type 2 diabetes. Diabetes. 2008;57(4):945-957.

17. Szymanowski M, Estebanez MS, Padidela R, Han B, Mosinska K, Stevens A, Damaj L, Pihan-Le Bars F, Lascouts E, Reynaud R, Ferreira C, Bansept C, de Lonlay P, Saint-Martin C, Dunne MJ, Banerjee I, Arnoux JB. mTOR inhibitors for the treatment of severe congenital hyperinsulinism: perspectives on limited therapeutic success. J Clin Endocrinol Metab. 2016;101(12):4719-4729.

18. Rovira J, Ramírez-Bajo MJ, Banon-Maneus E, Moya-Rull D, Ventura-Aguiar P, Hierro-Garcia N, LazoRodriguez M, Revuelta I, Torres A, Oppenheimer F, Campistol JM, Diekmann F. mTOR inhibition: reduced insulin secretion and sensitivity in a rat model of metabolic syndrome. Transplant Direct. 2016; 2(2):e65.

19. Johnston O, Rose CL, Webster AC, Gill JS. Sirolimus is associated with new-onset diabetes in kidney transplant recipients. J Am Soc Nephrol. 2008;19(7):1411-1418.

20. Dastamani A, Güemes M, Walker J, Shah P, Hussain K. Sirolimus precipitating diabetes mellitus in a patient with congenital hyperinsulinaemic hypoglycaemia due to autosomal dominant ABCC8 mutation. J Pediatr Endocrinol Metab. 2017;30(11):1219-1222.

21. Houde VP, Brûlé S, Festuccia WT, Blanchard PG, Bellmann K, Deshaies Y, Marette A. Chronic rapamycin treatment causes glucose intolerance and hyperlipidemia by upregulating hepatic gluconeogenesis and impairing lipid deposition in adipose tissue. Diabetes. 2010;59(6):1338-1348.

22. Shah P, Arya VB, Flanagan SE, Morgan K, Ellard S, Senniappan S, Hussain K. Sirolimus therapy in a patient with severe hyperinsulinaemic hypoglycaemia due to a compound heterozygous ABCC8 gene mutation. J Pediatr Endocrinol Metab. 2015;28(5-6):695-699.

23. Güemes M, Shah P, Roženková K, Gilbert C, Morgan K, Hussain K. Severe hyperinsulinaemic hypoglycaemia in Beckwith-Wiedemann syndrome due to paternal uniparental disomy of $11 \mathrm{p} 15.5$ managed with sirolimus therapy. Horm Res Paediatr. 2016;85(5):353-357.

24. Amato LA, Quigley CA, Neville KA, Hameed S, Verge CF, Woodhead HJ, Walker JL. Sirolimus treatment of severe congenital hyperinsulinism. Int J Pediatr Endocrinol. 2015 (Suppl 1):P123.

25. Abraham MB, Shetty VB, Price G, Smith N, Bock M, Siafarikas A, Resnick S, Whan E, Ellard S, Flanagan SE, Davis EA, Jones TW, Hussain K, Choong CS. Efficacy and safety of sirolimus in a neonate with persistent hypoglycaemia following near-total pancreatectomy for hyperinsulinaemic hypoglycaemia. J Pediatr Endocrinol Metab. 2015;28(11-12):1391-1398.

26. Minute M, Patti G, Tornese G, Faleschini E, Zuiani C, Ventura A. Sirolimus therapy in congenital hyperinsulinism: a successful experience beyond infancy. Pediatrics. 2015;136(5):e1373-e1376.

27. Kara CYG, Dermibirlek H, Flanagan SE, Ellard S, Hussain K, Aydin M. Efficacy and safety of sirolimus (mTOR inhibitor) in two patients with diazoxide-unresponsive hyperinsulinemic hypoglycemia. J Clin Res Pediatr Endocrinol. 2015;7(2):86.

28. Ünal S, Gonüla D, Uçaktürk A, Bilgin BS, Flanagan SE, Gürbüz F, Tayfun M, Elmaoğulları S, Araslı A, Demirel F, Ellard S, Hussain K. A novel homozygous mutation in the KCNJ11 gene of a neonate with congenital hyperinsulinism and successful management with sirolimus. J Clin Res Pediatr Endocrinol. 2016;8(4):478-481.

29. Loke KY, Anjian AS, Yijuan YL, Li CHW, Güemes M, Hussain K. Sirolimus therapy in a child with partially diazoxide responsive hyperinsulinaemic hypoglycaemia. Endocrinol Diabetes Metab Case Rep. 2016;2016:16-0043.

30. Haliloglu B, Tüzün H, Flanagan SE, Celik M, Kaya A, Ellard S, Özbek MN. Sirolimus-induced hepatitis in two cases with hyperinsulinemic hypoglycemia. J Clin Res Pediatr Endocrinol. 2017; 10(3):279-283.

31. Al-Balwi R, Al-Atawi M, Al-Otaibi A, Babiker O, Al-Mutair A. Sirolimus in the treatment of three infants with diffuse congenital hyperinsulinism. J Pediatr Endocrinol Metab. 2017;30(9):1013-1017.

32. Korula S, Chapla A, Priyambada L, Mathai S, Simon A. Sirolimus therapy for congenital hyperinsulinism in an infant with a novel homozygous KCNJ11 mutation. J Pediatr Endocrinol Metab. 2018; 31(1):87-89.

33. Fiebrich HB, Siemerink EJ, Brouwers AH, Links TP, Remkes WS, Hospers GA, de Vries EG. Everolimus induces rapid plasma glucose normalization in insulinoma patients by effects on tumor as well as normal tissues. Oncologist. 2011;16(6):783-787.

34. Beltrand J, Caquard M, Arnoux JB, Laborde K, Velho G, Verkarre V, Rahier J, Brunelle F, NihoulFékété C, Saudubray JM, Robert JJ, de Lonlay P. Glucose metabolism in 105 children and adolescents after pancreatectomy for congenital hyperinsulinism. Diabetes Care. 2012;35(2):198-203. 
35. Leiter SM, Parker VER, Welters A, Knox R, Rocha N, Clark G, Payne F, Lotta L, Harris J, GuerreroFernández J, González-Casado I, García-Miñaur S, Gordo G, Wareham N, Martínez-Glez V, Allison M, O’Rahilly S, Barroso I, Meissner T, Davies S, Hussain K, Temple K, Barreda-Bonis AC, Kummer S, Semple RK. Hypoinsulinaemic, hypoketotic hypoglycaemia due to mosaic genetic activation of PI3kinase. Eur $J$ Endocrinol. 2017;177(2):175-186.

36. Schachter AD, Benfield MR, Wyatt RJ, Grimm PC, Fennell RS, Herrin JT, Lirenman DS, McDonald RA, Munoz-Arizpe R, Harmon WE. Sirolimus pharmacokinetics in pediatric renal transplant recipients receiving calcineurin inhibitor co-therapy. Pediatr Transplant. 2006;10(8):914-919.

37. Arya VB, Senniappan S, Demirbilek H, Alam S, Flanagan SE, Ellard S, Hussain K. Pancreatic endocrine and exocrine function in children following near-total pancreatectomy for diffuse congenital hyperinsulinism. PLoS One. 2014;9(5):e98054. 